\title{
Spectrum of cytological finding in superficial lymphnode enlargement in a tertiary care center - retrospective study
}

\author{
T. Elavarasan ${ }^{1}$, M. S. Shruthi ${ }^{2}$, R. D. Puvitha ${ }^{3}$
}

${ }^{1}$ Dr. T. Elavarasan, Associate Professor, ${ }^{2}$ Dr M. S. Shruthi, Assistant Professor, ${ }^{3}$ Dr R. D. Puvitha, Associate Professor, All authors are affiliated with Department of Pathology, Government Dharmapuri, Medical College, Dharmapuri, Tamilnadu, India.

Address for Correspondence: Dr. M. S. Shruthi, Assistant Professor, Department of Pathology, Government Dharmapuri, Medical College, Dharmapuri,Tamilnadu, Email id: froots_dr@yahoo.co.in

\begin{abstract}
Introduction: Lymphadenopathy refers to lymph nodes that are abnormal in size, consistency or number. It is one of the commonest and significant clinical presentations of patients, attending the outdoor clinics in most hospitals. Superficial lymphadenopathy ranked among the most common clinical findings encountered in the etiology of lymph nodes enlargement range from spectrum of infections, reactive hyperplasia to malignant diseases. Diagnosing these lesions poses a major challenge to the clinicians. FNAC is an easy, safe, reliable, rapid and inexpensive method for diagnosing enlarged lymph nodes with a high degree of accuracy. The aim of our study is to study and evaluate the spectrum of cases of superficial lymph node enlargement in our region. Materials and methods: The retrospective study was done in the cytological section of the department of pathology in our hospital over a period of two years. Patients who visited the OPD of our hospital, withcomplaints of lymph node enlargement weresent for FNAC for proper diagnosis. The data were retrieved, compiled, summarized and statistically analyzed. Results: Of the 770 cases studied, the most common cause of lymphadenopathy was reactive lymphadenitis with 438 cases $(56.8 \%)$. The next common diagnosis was found to be granulomatous lymphadenitis with 197 cases (25.5\%) followed by suppurative lymphadenitis in 68 cases (8.8\%), metastatic lymphadenopathy in 61 cases $(7.9 \%)$ and malignant lymphoma in 6 cases $(0.7 \%)$. Conclusion: FNAC is an easy, simple, safe and inexpensive method of diagnosing lymph node lesions.
\end{abstract}

Key Words: FNAC, Lymphadenopathy, Lymph node enlargement, cytology

\section{Introduction}

Swellings in any part of the body brings anxiety to the patient. Lymph node enlargement is one of the common presentations in outpatient departments. Lymphadenopathies can be due to various causes ranging from a simple reactive to frightful malignancy. These malignancies could be primary in origin or due to secondary deposits from an unknown primary $[1,2]$.

Superficial lymphadenopathy is commonly due to some underlying pathology.Infectious diseases are considered to be the major causes of lymphadenopathy, in that tuberculosis is common in tropical countries. Tuberculous lymphadenopathy is the commonest form

Manuscript received: $16^{\text {th }}$ August 2017

Reviewed: $26^{\text {th }}$ August 2017

Author Corrected: $3^{\text {rd }}$ September 2017

Accepted for Publication: $8^{\text {th }}$ September 2017 of extrapulmonary tuberculosis [1]. In developing countries, almost two third of the cases are due to tuberculosis, whereas in the developed countries, it is the metastatic malignancies that account for themost of the cases. Diagnosing these lesions poses a major challenge to the clinician. There are various methods of investigative modalities for diagnosing these lymph nodes like fine needle aspiration cytology (FNAC), core biopsy and excision biopsy. However, FNAC has become an authentic tool for assessment and diagnosis of superficial lymph node enlargement. Diagnosing metastatic lesions helps in avoiding unnecessary biopsies in patients, and also helps us in guiding the clinician for the search of an unknown primary [3]. FNAC is also most useful for the selection of representative node for biopsy, for thediagnosis of 
Research Article

recurrent lymphoma, for staging purpose and for monitoring the treatment [4].

Fine needle aspiration cytology is a reliable, simple, safe, rapid and inexpensive method of establishing the diagnosis of cervical lymphadenopathy. It also gives a great relief to the anxiety of thepatients and their relatives, as it is a safe, almost painless requiring no anesthesia,as it's a OPD procedure, and the report is available within a short span of time, with negligible complications [5].

With appropriate staining techniques, FNAC allows a provisional diagnosis to be made at the patient's initial presentation and, thus, helps us in guiding appropriate specialist referral and suggesting further investigations [6]. Our present retrospective study aims to find out the spectrum of diseases responsible for the lymph node enlargement.

\section{Aim of study:}

- To study the spectrum of cases of superficial lymph node enlargement in our region

- To study the distribution of various lesions with respect to age and gender.

- To find out the number of cases where FNAC of the lymph node picked up an unsuspected malignancy (primary or secondary).

\section{Materials and Methods}

Study design:The present study is a retrospective study of 770 cases over a period of two years.

Setting: The study was performed in the cytological department of Government Dharmapuri Medical College and Hospital. All the patients had chief complaint of lymph node enlargement. FNAC was performed using 23 gauge needle attached to a syringe.

In each procedure, an average of four to fivepasses were usually performed and the aspirated materials were smeared into two to three slides.

Slides were alcohol fixed and stained with haematoxylin and eosin and using D.P.X mountant and slides were prepared for cytological examination.

The reporting was done by experienced cytologists, and the data of reported cases over past two years (January 2015- December 2016) were collected and categorized.

The data were retrieved, compiled, summarized and statistically analyzed. Data was analyzed using SPSS24.

Inclusion criteria: All the superficially enlarged lymph nodes

Exclusion criteria: Inadequate acellular smears.

\section{Results}

Table 1: In our present study a total of 770 cases were studied. The age group of the patients ranged from 1 year to 88 years, with males being slightly more common than females (1.2:1).

Table 1: Gender distribution of patients of lymphadenopathy.

\begin{tabular}{|c|c|c|}
\hline Gender & Frequency & Percent \\
\hline Males & 419 & 54.4 \\
\hline Females & 351 & 45.6 \\
\hline Total & 770 & 100 \\
\hline
\end{tabular}

Among all the age groups studied, cervical lymphadenopathy is most common site of lymphnode enlargement. Majority of cases belonged to age group of 15-45 years with 333 cases of cervical lymphnode enlargement and 41 cases of axillary lymphnode enlargement.

This was followed with 188 cases of cervical lymphadenopathy and six cases of axillary lymphadenopathy in the age group of under 14 years (Table 2).

The youngest patient presented with cervical lymphadenopathy and was diagnosed as reactive lymphadenitis whereas the oldest patient presented with supraclavicular lymphnode enlargement which was found to be metastatic with adenocarcinomatous deposits. 
Table-2: Comparison of age with site of patients of lymphadenopathy.

\begin{tabular}{|c|c|c|c|c|c|c|}
\hline Age groups & Cervical & Axillary & Inguinal & Pre auricular & Post auricular & Parasternal \\
\hline Under 14 & 188 & 6 & 9 & 1 & 1 & 0 \\
\hline $15-45$ & 333 & 41 & 12 & 1 & 1 & 2 \\
\hline $46-65$ & 112 & 18 & 10 & 1 & 0 & 0 \\
\hline 66 and older & 24 & 5 & 3 & 2 & 2 & 0 \\
\hline Total & 657 & 70 & 34 & 5 & 2 \\
\hline
\end{tabular}

On considering age group and diagnosis, it was found that in all the age groups, the most common diagnosis was reactive lymphadenitis, with majority of cases in age group of 15-45 years. This was followed by granulomatous lymphadenitis which was also seen in the age group of 15-45 years. It was observed that majority of cases of metastatic lymph node enlargement was seen in the age group of 46-65 years. There were four cases of lymphoproliferative disorders in the age group of 15-45 years (Table 3 ).

Table-3: Comparison of age with diagnosis of patients of lymphadenopathy.

\begin{tabular}{|c|c|c|c|c|c|c|}
\hline Age groups & Reactive & Granulomatous & Suppurative & Metastatic & LPD & Total \\
\hline Under 14 & 171 & 22 & 11 & 0 & 1 & 205 \\
\hline $15-45$ & 204 & 139 & 37 & 6 & 4 & 390 \\
\hline $46-65$ & 52 & 35 & 17 & 36 & 1 & 141 \\
\hline 66 and older & 11 & 1 & 3 & 19 & 0 & 34 \\
\hline Total & 438 & 197 & 68 & 61 & 6 & 770 \\
\hline
\end{tabular}

Of 770 cases studied, cervical lymph node enlargement is the most common site which was followed by axillary lymph node enlargement (Table 4).

Table-4: Site distribution of patients of lymphadenopathy.

\begin{tabular}{|c|c|c|}
\hline Site & Frequency & Percent \\
\hline Cervical & 657 & 85.45 \\
\hline Axillary & 70 & 9.09 \\
\hline Inguinal & 34 & 4.41 \\
\hline Pre auricular & 5 & 0.64 \\
\hline Post auricular & 2 & 0.12 \\
\hline Parasternal & 2 & 0.25 \\
\hline Total & 770 & 100 \\
\hline
\end{tabular}

It was observed in our study that the most common diagnosis was that of reactive lymphadenitis which was followed by granulomatous lymphadenitis. There were also 68 cases of suppurative lymphadenitis and 61 cases of metastatic lymph node enlargement (Table 5).

Table 5: Diagnosis distribution of patients of lymphadenopathy.

\begin{tabular}{|c|c|c|}
\hline Diagnosis & No of cases & Percentage \\
\hline Reactive & 437 & 56.8 \\
\hline Granulomatous & 198 & 25.7 \\
\hline Suppurative & 68 & 8.8 \\
\hline Metastatic LN & 61 & 7.9 \\
\hline LPD & 6 & 0.8 \\
\hline Total & 770 & 100 \\
\hline
\end{tabular}


Research Article

On comparing the site and diagnosis it was found that in all groups of lymph nodes, reactive lymphadenitis was the most common finding, which was followed by granulomatous lymphadenitis. Metastatic lymphadenopathy was most commonly seen in the cervical group of lymph nodes which was followed by the axillary group of lymph nodes. It was also observed that the lymphoproliferative disorder was most commonly seen in cervical group of lymph nodes (Table 6).

Table 6: Comparison of site and diagnosis of patients of lymphadenopathy.

\begin{tabular}{|c|c|c|c|c|c|c|}
\hline \multirow{2}{*}{ Site } & \multicolumn{4}{|c|}{ Diagnosis } & Total \\
\cline { 2 - 8 } & Reactive & Granulomatous & Suppurative & Metastatic & LPD & $\mathbf{7 7 0}$ \\
\hline Cervical & 368 & 180 & 49 & 55 & 6 & 658 \\
\hline Axillary & 37 & 15 & 14 & 4 & 0 & 70 \\
\hline Inguinal & 25 & 3 & 4 & 2 & 0 & 34 \\
\hline Preauricular & 5 & 0 & 0 & 0 & 0 & 5 \\
\hline Postauricular & 1 & 0 & 0 & 0 & 0 & 1 \\
\hline Parasternal & 1 & 0 & 1 & 0 & 0 & 2 \\
\hline
\end{tabular}

Among the metastatic lymphadenopathies, SCC deposits are the most common, which is followed by adenocarcinomatous deposits, whichis commonly seen in the cervical group of lymph nodes (Table 7 ).

Table 7: Comparison of site with diagnosis in cases of metatstatic lymphadenopathy.

\begin{tabular}{|c|c|c|c|c|}
\hline Site & SCC & Adenocarcinoma & Malignant melanoma & Total (71) \\
\hline Cervical & 45 & 10 & 0 & 55 \\
\hline Axillary & 0 & 4 & 0 & 4 \\
\hline Inguinal & 1 & 0 & 1 & 2 \\
\hline
\end{tabular}

\section{Discussion}

Lymph node enlargement is one of the common presentations seen in patients, who are attending to medical and surgical OPDs. It may be due to various reasons, ranges from reactive, inflammatory to malignancies. Sometime, the patient present withlymphnode enlargement as initial presentation, as in case ofsecondary deposits, thus urging the clinician to search for the primary.Our results are comparable with other Indian study with males more affected than females (1.2:1) and where majority of the cases belonged to age group of 15-45 years (40.1\%), with maximum number of cases being reactive lymphadenitis (52.3\%)[7]. We also observed in our study that majority of the patients belonging to pediatric age group, under 14 years, presented with reactive lymphadenitis in 171 cases (39.04\%), which is followed by 22 cases (11.1\%) of granulomatous lymphadenitis.These results are comparable with other Indian studies, where, in older age, more than 65 years of age, the major cause of lymphadenopathy is metastatic deposits [8].

Legends for illustrations

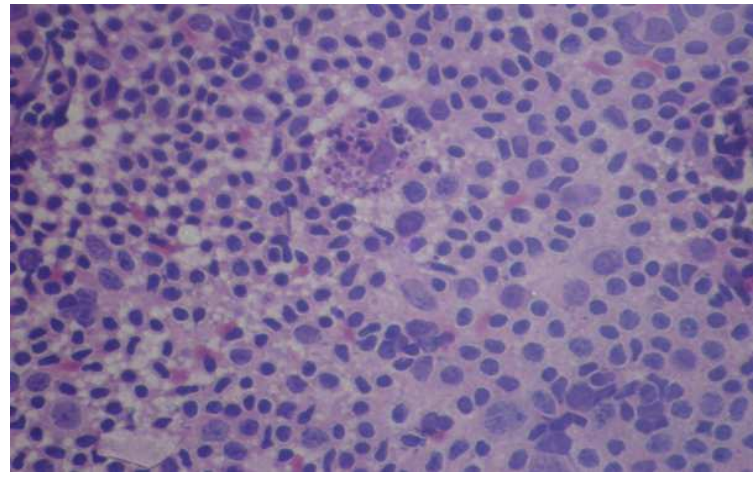

Fig 1: Smear shows reactive lymphoid cells with tingible body macrophages. (H\&E stain;X400)

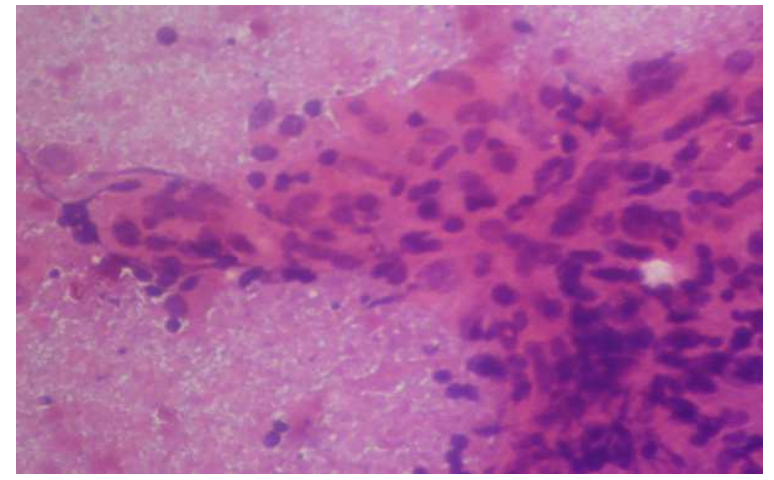

Fig 2. Smear shows epithelioid cell granulomas along with caseous necrosis in the background. (H\&E stain;x400) 
Research Article

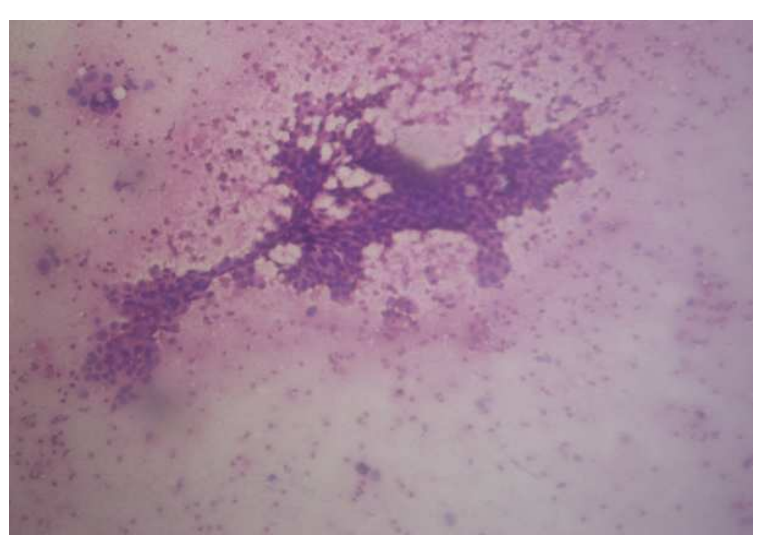

Fig 3. Smear shows clusters of atypical epithelial cells with prominent nucleoli and dense cytoplasm (H \& E stain; x400)

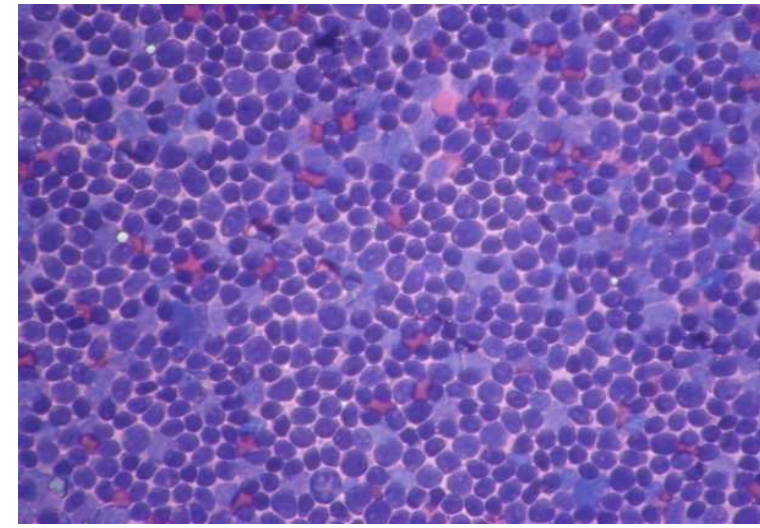

Fig4: Smear shows monotonous sheets of small to medium sized lymphoid cells. (H\&E stain; $x 400)$

Out of 770 cases of superficial lymphadenopathies 703 cases (91\%) showed benign lesion, whereas, 67 cases (8.7\%) showed malignancy. Similar findings were observed in other studies done by Gaur R et al[7]. However, this is in contrast to studies done in western countries which showed an increase in malignant lesions than benign lesions $[4,8]$. This could be owing to the reason that, in our study, bulk of diseaseswere of reactive in nature, due to infections or tubercular lesions which are uncommon in western countries [4].

Among the benign lesions, reactive lymphadenitis was most common with 437 cases (56.8\%), followed by chronic granulomatous lymphadenitis with 198 cases $(25.7 \%)$. This is in comparison with other studies which showed similar observations [4,9]. Sharma $\mathrm{P}$ et al reported $6.11 \%$ cases of acute suppurative lymphadenitis in their study which is concordance with our study where there are 68 cases $(8.8 \%)$ of acute suppurative lymphadenitis[1].

Among the malignant lesions, there were cases of both metastatic lymphadenopathies as well as lymphoproliferative disorders. It was observed that metastatic lymphadenopathy constitutes about $7.9 \%$ of cases which is similar to findings in other Indian studies by Attaullah $\mathrm{M}$ et al and Steel B et al[3,8].

In our present study, we observed that most common site of lymph node enlargement was cervical group of lymph nodes, followed by axillary group of lymph nodes and inguinal group of lymph nodes. Similar observations were also reported by other Indian studies [3,7,9]. In all these group of lymph nodes, the most common diagnosis was reactive lymphadenitis followed by granulomatous lymphadenitis which is similar to studies done by Pandey P et al[4].

Among the cases of granulomatous lymphadenitis, the most common site in our study is cervical group of lymph nodes which was in concordance with study done earlier[10]. Cervical group of lymph nodes were the most common site of metastatic deposits in our study. This is in comparison to the studies done earlier[10]. Most common metastatic deposits were squamous in origin and could probably be from the upper aero digestive tract. Similar findings were also observed in other Indian studies [11,12].

Smears showed from these cases showed tumor cells in clusters, sheets and scatters. Occasional cells show individual cell keratinization with necrosis in the background [13]. In other studies, the most common metastatic subtype was adenocarcinoma.

However, sometimes it becomes difficult to distinguish between adenocarcinoma and poorly differentiated squamous cell carcinoma, when the cell clusters show thick nuclear membrane and prominent nucleoli [11]. In the axillary group of lymph nodes, itsadenocarcinomatous deposits only, with primary in the breast. These smears are highly cellular with loosely cohesive clusters of malignant cells. Individual ductal cells have moderate to abundant cytoplasm with pleomorphic nuclei and prominent single to multiple nucleoli. Tumor giantcells were also seen in one or two cases[11]. 
We also encountered a single case of malignant melanoma deposits in the inguinal lymph node from a patient with primary malignant melanoma in the ipsilateral foot $[11,14]$. The smear studied shows scattered pleomorphic cells with few binucleate or multinucleate forms with 1-2 prominent nucleoli. Intra and extracellular melanin pigment were seen. There was also a case of squamous cell carcinoma deposits in the inguinal lymph node from a male patient with primary penilecarcinoma. Among the primary lymph node malignancies, there were six cases $(0.8 \%)$ reported which was in concordance with study done by Arakeri et al[15].

\section{Conclusion}

Cytomorphological study of lymph nodes helps us in diagnosing whether the lymphadenopathy is due to reactive hyperplasia, granulomatous disease, metastatic malignancy or lymphomas.

This helps us in avoiding unnecessary biopsies in patients with reactive disease, granulomatous disease and metastatic malignancies.

As the cost of medical facilitiesare increasing, FNAC is a less expensive technique which is relatively easy to perform and provides with immediate results in the diagnosis of superficial lymphadenopathies.

It not only helps in diagnosis but also acts as screening technique for lymph node pathologies like malignancies both primary and metastatic.

The present study shows that FNAC is an important diagnostic tool for the diagnosis of majority of cases enlarged superficial lymphnodes, done in most backward district where expensive techniques are not feasible and where patient compliance is poor.

Funding: Nil, Conflict of interest: None initiated, Permission from IRB: Yes

\section{References:}

1. Sharma P, Rana S, Gill MK, Singh P, Satarkar RN, Kalhan S. Spectrum of lymph node lesions on cytology in rural Haryana: a retrospective analysis. Int J Res Med Sci. 2015 May;3(5):1125-30.doi: 10. 5455/ 2320-6012. ijrms 20150518

2. Vasilj A, Katovic SK. Fine needle aspiration cytology of head and neck lymph nodes in a ten -year period - single center experience. Acta Clin Croat. 2015 Sep; 54(3) :315-8.

3. Attaullah M, Shah W, Pervez SN, Khan S, Jehan S, Rahim S. Cytomorphological pattern of superficially mphadeno pathy. Gomal J Med Sci. 2014 oct-nov;12 (4): 197-200.
4. Pandey P, Dixit A, Mahajan NC. The diagnostic value of FNAC in assessment of superficial palpable lymph nodes: a study of 395 cases. Al Ameen J Med Sci. 2013 Oct-Dec; 6(4) :320-7

5. Kochhar AK, Puri PL, Kochhar S. Role of fine needle aspiration cytology in assessment of cervical Lymphadenopathy. International Journal of Medical Research and Review. 2016 June; 4(6): 876-80. doi: 10. 17511/ijmrr.2016.i06.03.

6. Stewart CJR, Duncan JA, Farquharson M, Richmond J. Fine needle aspiration cytology diagnosis of malignant lymphoma and reactive lymphoid hyperplasia. J ClinPathol 1998 March; 51(3):197-203.

7. Gaur R,Woike P. Spectrum of Cytological Findings In Patients with Superficial Lymphadenopathy: A Five Year Retrospective Study. JMSCR 2015 Oct; 3 (10) : 7933-9. doi: http://dx.doi.org/10.18535/jmscr/v3i10.37

8. Steel BL, Schwartz MR, Ramzy I. Fine needle aspiration biopsy in the diagnosis of lymphadenopathy in 1, 103 patients. Role, limitationsand analysis of diagnostic pitfalls. ActaCytol.1995Jan-Feb;39(1):76-81.

9. Mohanty R, Wilkinson A. Utility of Fine Needle Aspiration Cytology of Lymph. IOSR Journal of Dental and Medical Sciences. 2013 July- Aug;8:(5)13-18.

10. Chute DJ, Stelow EB. Cytology of head and neck squamous cell carcinoma variants. DiagnCytopathol. 2010 Jan;38(1):65-80. doi: 10.1002/dc.21134.

11. Ghartimagar D, Ghosh A, Ranabhat S, Shrestha MK, Narasimhan R, Talwar OP. Utility of fine needle aspiration cytology in metastatic lymph nodes Journal of Pathology of Nepal. 2011 Oct; 1(2):92 -5.

12. Biradar SS, Masur DS. Spectrum of Lymph Node Lesions by Fine Needle Aspiration Cytology: A Retrospective Analysis.Annals of Pathology and Laboratory Medicine. 2017 May-June; 4(3):264-7.doi: 10. 21276/apalm.1355. 
13. Giri S, Singh K. Role of fine needle aspiration cytology in evaluation of patients with superficial lymphadenopathy Int J Biol Med Res. 2012 ; 3(4): 2475-9.

14. Tapani Tikkakoski, T. Siniluoto, A. Ollikainen, M. Päivánsalo, P. Lohela M. Apaja- Sarkkinen. Ultrasound- Guided Aspiration Cytology of Enlarged
Lymph Nodes Acta Radiologica.1991;32(1):53-6. doi: http://dx.doi.org/10.3109/02841859109177508.

15. Arakeri S, Gandhi N. Prospective Study of Fine Needle Aspiration Cytology of Lymph Nodes of The Head And Neck Region over a 2 Year Period with Histopathological Correlation. Indian Journal of Research 2014; 3(2) 229-31.

\section{How to cite this article?}

T. Elavarasan, M. S. Shruthi, R. D. Puvitha. Spectrum of cytological finding in superficial lymphnode enlargement in a tertiary care center - retrospective study.Trop J Path Micro 2017;3(3):347-353.doi:10.17511/jopm.2017.i3.21. 